\title{
IN VITRO QUALITATIVE ASSAY OF BENZYLTIN DERIVATES AS BACTERIAL GROWTH INHIBITORS.
}

Romina A. Ocampo, ${ }^{\text {ab }}$ María G. Montiel Schneider, ${ }^{\text {ab }}$ Andrea R. Costantino, $^{\text {ab }}$ Sandra D. Mandolesi, ${ }^{*^{a}}$ Liliana C. Koll.* ${ }^{\mathrm{ab}}$

a Instituto de Química del Sur (INQUISUR), Departamento de Química, Universidad Nacional del Sur, Avenida Alem 1253, 8000 Bahía Blanca, Argentina.

${ }^{b}$ CONICET, Argentina. E-mail: rocampo@uns.edu.ar, Ickoll@criba.edu.ar, sdmando@criba.edu.ar.

\section{Abstract:}

We performed an in vitro qualitative assay, and evaluated the activity of benzyltri- $n$ butyltin (I) and 3,5-dimethoxybenzyltri-n-butyltin (II) against the growth of two bacterial strains: Staphylococcus aureus (Gram-positive) and Escherichia Coli (Gram-negative), using agar diffusion method. In all cases Merck Art 5273 broth was employed. THF was used both as the solvent of choice for the organometallic compound (since the organotin compounds are not water soluble) and as a negative control. Different concentrations I and II were prepared and the activity was determined by measuring the diameter of the inhibition zone (in $\mathrm{cm}$ ).

Keywords: organotin compounds, bacterial growth inhibitors, agar well diffusion method.

\section{Introduction}

Bacteria can be classified into two main groups according to their response to the most important staining method in Microbiology, designed by the Danish bacteriologist Hans Christian Gram,: Gram-positive (which at the end of the process are stained blue) and Gramnegative (which are stained red). The Gram staining reflects the difference in the structure of the bacterial wall (Fig. 1). This distinction is very important not only for the classification of bacteria but also for the correlation between the activity of certain antibiotics and the bacterial wall structure.

\section{Figure 1}

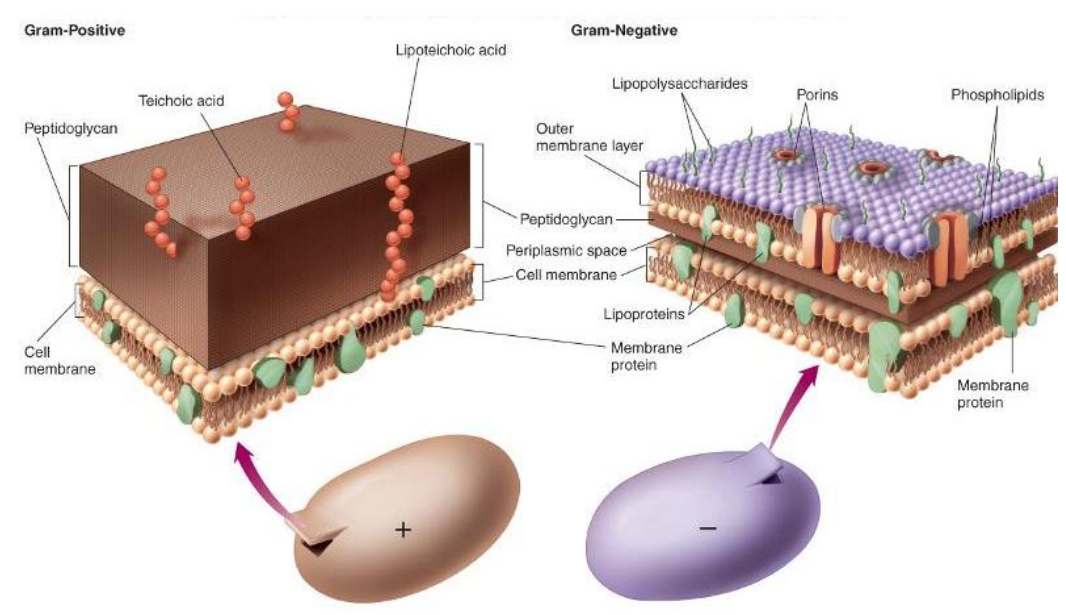


In our study, two bacterial strains broth cultures were used: a Gram positive (Staphylococcus aureus), and Gram-negative (Escherichia coli).

\section{S. aureus.}



E. coli.



Organotin compounds have shown a wide spectrum of biological effects and have been extensively studied as fungicides, bactericides, acaricides and wood preservative. ${ }^{1}$ A large number of papers have reported the use of organotin compounds as bacterial growth inhibitors. ${ }^{2}$ The biocide activity of tribenzyl- and dibenzyltin compounds has been informed, ${ }^{3}$ but the effect that the methoxyl group in the aromatic ring could have on the activity of the compounds has not been reported in previous literature. Therefore, we studied the inhibition of bacterial growth produced by organotin compounds I and II using the disk diffusion method.

To perform the method, filter paper discs were impregnated with known amounts (stock solution and dilutions ) of the organotin compounds. Then, a Petri dish was inoculated with a bacterial strain, and the paper discs impregnated with different concentrations of the corresponding benzyltin compounds were placed on the surface (Fig. 2). The drug diffused from the disk through the gel. In all cases the plates were left in the refrigerator for 48 hours to allow for optimal diffusion of the compound and then incubated in an oven at $37^{\circ} \mathrm{C}$ for 48 hours to allow bacteria to grow. After growth, some discs were surrounded by a clear halo (no growth), which indicates bacterial growth inhibition produced by the corresponding tin compound. Large inhibition zones, indicating greater susceptibility of the organism to the drug.



Figure 2

\section{Results and Discussions}

In all cases Muller Hinton agar broth (MHB) Merck Art 5273 1.2\% was used as solid medium for antibiotic

For inhibition assays disk diffusion method were performed, using a culture broth of each strain to antibiotics in early stationary phase.

Since the agar broadcast medium is aqueous and organotin derivatives are not soluble in water, solubility tests were performed on the compounds I and II in water-miscible solvents, so that they can diffuse freely in the culture medium. Thus, the bacterial inhibition tests were conducted for selected co-solvents (DMSO and THF) to rule out inhibition due to the solvent. THF was selected to performing the test in the absence of organotin inhibition. 


\section{Negative control (THF).}

Serial dilutions were prepared in half the solvent (THF) in water to a concentration of $6.25 \%$, performing the agar diffusion method on each of the above strains.

Inhibition assays using solutions of organotin compounds:

Two stock solutions were prepared: * Benzyltri- $n$-butyltin (I) $0.25 \mathrm{M}$ in THF.

* 3,5-dimetoxibenciltri- $n$-butyl tin (II) $0.25 \mathrm{M}$ in THF.

Each solution were diluted to $6.25 \%$, in order that the results can be compared with the negative control.

The results were tabulated, using arbitrary units to express the inhibition zones (Table 1).

Table 1. Inhibition of bacterial growth by using different concentrations of the compounds I and II.

\begin{tabular}{c|c|c|c}
\hline \multirow{2}{*}{ Benzyltin compound } & Mother solution & \multicolumn{2}{|c}{ Inhibition Zone } \\
\cline { 3 - 4 } & concentration & E. coli & S. aureus \\
& & & \\
& $100.00 \%$ & $0.35 \mathrm{~cm}$ & $0.50 \mathrm{~cm}$ \\
& $50.00 \%$ & $0.15 \mathrm{~cm}$ & $0.25 \mathrm{~cm}$ \\
& $25.00 \%$ & $0.10 \mathrm{~cm}$ & $0.15 \mathrm{~cm}$ \\
& $12.50 \%$ & $0.00 \mathrm{~cm}$ & $0.10 \mathrm{~cm}$ \\
& $6.25 \%$ & $0.00 \mathrm{~cm}$ & $0.00 \mathrm{~cm}$ \\
\hline & $100.00 \%$ & $0.50 \mathrm{~cm}$ & $1.00 \mathrm{~cm}$ \\
& $50.00 \%$ & $0.25 \mathrm{~cm}$ & $0.70 \mathrm{~cm}$ \\
& $25.00 \%$ & $0.15 \mathrm{~cm}$ & $0.20 \mathrm{~cm}$ \\
& $12.50 \%$ & $0.05 \mathrm{~cm}$ & $0.15 \mathrm{~cm}$ \\
& $6.25 \%$ & $0.01 \mathrm{~cm}$ & $0.10 \mathrm{~cm}$ \\
\hline & $100.00 \%$ & $0.30 \mathrm{~cm}$ & $0.25 \mathrm{~cm}$ \\
& $50.00 \%$ & $0.10 \mathrm{~cm}$ & $0.10 \mathrm{~cm}$ \\
& $25.00 \%$ & $0.00 \mathrm{~cm}$ & $0.00 \mathrm{~cm}$ \\
& $12.50 \%$ & $0.00 \mathrm{~cm}$ & $0.00 \mathrm{~cm}$ \\
& $6.25 \%$ & $0.00 \mathrm{~cm}$ & $0.00 \mathrm{~cm}$ \\
\hline
\end{tabular}

Table 1 shows that $\boldsymbol{S}$. aureus strain is more susceptible to the inhibition growth effect of the organotin compounds than E.coli. The latter strain yield no significant differences with respect to the THF control, especially in the assay with benzyltri- $n$-butyltin. For both strains, larger inhibition zones were obtained with 3,5 dimetoxibenciltri-n-butyltin (II). 
Graphic 1: Bacterial growth inhibition on E. coli to test the compound I.
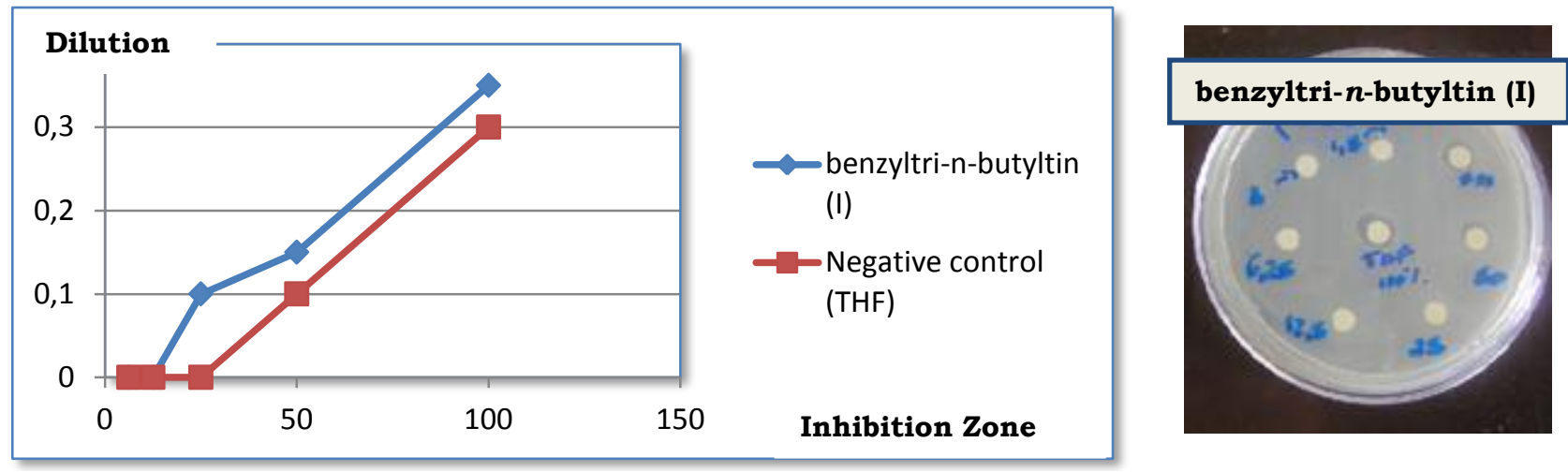

Graphic 2: Bacterial growth inhibition on E. coli to test the compound II.


Graphic 3: Bacterial growth inhibition on S. aureus to test the compound I.

Graphic 4: Bacterial growth inhibition on S. aureus to test the compound II.

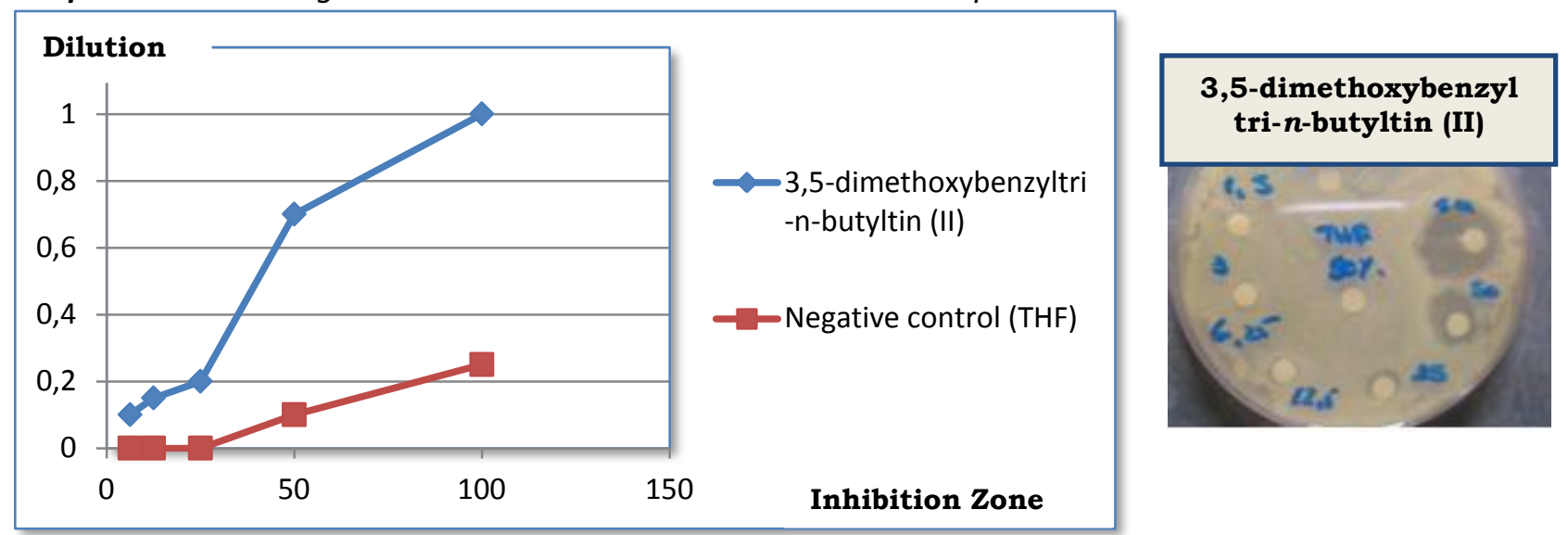

\section{Conclusions}

The results proved not only that the Gram-positive strain is more susceptible to the inhibition growth effect of the organotin compounds evaluated, but also that 3,5dimethoxybenzyltri- $n$-butyltin has higher antibacterial activity. According to this preliminary results we conclude that the presence of the methoxyl group in the aromatic ring would enhance the antibacterial activity of the organotin compound tested here.

In order to check if the preliminary results obtained are characteristic of strain or gender, we will expand the study to other Gram positive and Gram negative microorganims.

This first technique allowed us to see the type of inhibition exists in each strain with each of organotin compounds used, and to estimate the concentrations range that may then work in future studies of antibacterial activity by measuring two parameters: MIC (minimum inhibitory concentration) and MBC (minimum bactericidal concentration).

\section{Acknowledgments}

This work was supported by grants from ANPCyT (Capital Federal, Argentina), CONICET (Buenos Aires, Argentina) and Universidad Nacional del Sur (Bahía Blanca, Argentina). A fellowship from CONICET to ARC and GMS is acknowledged.

\section{Experimental}

\section{General methods}

Unless otherwise noted, all reagents were purchased from commercial suppliers and used without purification.

\section{In vitro antibacterial screening activity.}

The synthesized organotin compounds (I and II) were screened for their in vitro antibacterial activity against a gram-negative (Escherichia coli) and a gram-positive 
(Staphylococcus aureus) bacterial strains, by Inhibition Zone Method using agar well diffusion method.

\section{Principle}

Paper discs impregnated with specific test substances are placed on the surface of the Muller Hinton agar medium inoculated with the target organisms, which is recommended for the diffusion of antimicrobial agents as described in NCCLS approved standard. The plates are incubated and the zones of inhibition around each disc are measured.

\section{Reagents}

\section{Muller Hinton Agar Medium (1 L)}

The medium was prepared by dissolving $33.9 \mathrm{~g}$ of the commercially available Muller Hinton Agar Medium (HiMedia) in $1000 \mathrm{ml}$ of distilled water. The dissolved medium was autoclaved at $15 \mathrm{lbs}$ pressure at $121^{\circ} \mathrm{C}$ for 15 minutes. The autoclaved medium was mixed well and poured onto $100 \mathrm{~mm}$ petriplates $(25-30 \mathrm{ml} /$ plate) while still molten.

\section{Nutrient broth (1L)}

One litre of nutrient broth was prepared by dissolving $13 \mathrm{~g}$ of commercially available nutrient medium (HiMedia) in $1000 \mathrm{ml}$ distilled water and boiled to dissolve the medium completely. The medium was dispensed as desired and sterilized by autoclaving at $15 \mathrm{lbs}$ pressure (121으) for 15 minutes.

\section{Procedure}

Muller Hinton Agar plates were prepared and the test microorganisms were inoculated by the spread plate method. Filter paper discs approximately $6 \mathrm{~mm}$ in diameter were soaked with $15 \mu \mathrm{l}$ of the organotin compound dilution and placed in the previously prepared agar plates. Each disc was pressed down to ensure complete contact with the agar surface and distributed evenly so that they are no closer than $24 \mathrm{~mm}$ from each other, center to center. The agar plates then incubated at $37^{\circ} \mathrm{C}$. After 16 to 18 hours of incubation, each plate was examined. The resulting inhibition zones were uniformly circular with a confluent growth decreased. The diameters of the zones of complete inhibition were measured, including the diameter of the disc where the THF was used as control (NCCLS, 1997).

\section{References}

1. Nath, M.; Pokharia, S.; Yadav, R. Coordination Chemistry Reviews, 2001, 215, 99.

2. (a)Thodopunoori, K.; Alamudun, I.; Cervantes-Lee, F.; Gomez, F.; Carrasco, Y.; Pannell, K. J. Organomet. Chem. 2006, 1790. (b) Casas, A.; Castiñeiras, M.; Rodriguez-Arguelles, A.; Sánchez, J.; Sordo, A.; Vázquez, S.; Pinelli, P.; Lungui, P.; Ciancianaini, A.; Bonati, P.; Dall'Aglio, R.; Albertini; J. Inorg. Biochem., 1999, 76, 277. (c) Win, Y.; Teoh, S.; Vikneswaran, M.; Ha, S.; Ibrahim, P. Int. Phys. Sciences, 2010, 5, 1263.

3. (a) Rheman, W.; Badshah, A.; Baloch, M.K.; Hameed, G.; Khan, K.M. J. Ch. Chem. Soc., 2004, 51, 929. (b) Rehman, W.; Baloch, M.K.; Badshah, A.; Ali, S. J. Ch. Chem. Soc., 2005, 52, 231. (c) Shahzadi, S.; Shahid, K.; Ali, S.; Mazhar, M.; Badshah, A.; Ahmed, E.; Malik, A. Turk. J. Chem., 2005, 29, 273. 